University of Nebraska - Lincoln

DigitalCommons@University of Nebraska - Lincoln

Biological Systems Engineering: Papers and

Publications

Biological Systems Engineering

2010

Extrusion Systems: Components

Qi Fang

Banner Pharmacaps, Inc., High Point, North Carolina

Milford Hanna

University of Nebraska-Lincoln, mhanna1@unl.edu

Follow this and additional works at: https://digitalcommons.unl.edu/biosysengfacpub

Part of the Bioresource and Agricultural Engineering Commons, and the Industrial Technology

Commons

Fang, Qi and Hanna, Milford, "Extrusion Systems: Components" (2010). Biological Systems Engineering: Papers and Publications. 310.

https://digitalcommons.unl.edu/biosysengfacpub/310

This Article is brought to you for free and open access by the Biological Systems Engineering at DigitalCommons@University of Nebraska - Lincoln. It has been accepted for inclusion in Biological Systems Engineering: Papers and Publications by an authorized administrator of DigitalCommons@University of Nebraska Lincoln. 


\title{
Extrusion Systems: Components
}

\author{
Qi Fang
}

Research and Development, Banner Pharmacaps, Inc., High Point, North Carolina, U.S.A.

Milford A. Hanna

Biological Systems Engineering Department, Industrial Agricultural Products Center, University of Nebraska—Lincoln, Lincoln, Nebraska, U.S.A.

\begin{abstract}
An extrusion system can be very simple to very complex. The complexity, or versatility, of a particular system is determined by the range of feedstocks to be processed, the desired transformations of the feedstocks, and the desired form of the products resulting from the process. These determine the specific design requirements of the various components of an extrusion system.
\end{abstract}

\section{INTRODUCTION}

Extrusion refers to the forming of products to a desired shape and size by forcing the material through a die opening under pressure. It also involves thermal and mechanical energy input, which can trigger chemical reactions in the food being processed. Extrusion has been used extensively in the food industry to process a variety of raw materials into foods, including breakfast cereals, snacks, pastas, texturized vegetable protein, flat bread, meat products, and pet foods.

Depending on the products being processed, a complete extrusion system generally consists of storage bins, dry mix feeders, liquid pumps and meters, a preconditioner, an extruder assembly, a die, and a cutter (Figure 1). Each of the components will be discussed in detail.

\section{STORAGE BIN}

A storage bin is used for the storage of dry ingredients. It provides a buffer of raw material so that an extruder has a continuous and stable supply of feed ingredients. This bin is usually equipped with rotating blades to prevent bridging.

\section{DRY INGREDIENT FEEDERS}

Two types of dry feeders are normally used to feed extruders: volumetric feeders and gravimetric feeders. A volumetric feeder provides a constant volume of dry ingredients, but cannot guarantee a constant mass flow rate due to changes in density of feed material. Gravimetric feeders, on the other hand, control feed flow rate based on the mass delivered and, therefore, are more accurate feeding devices.

\section{Volumetric Feeding Devices}

Volumetric feeders deliver dry ingredients on a volume basis. Several types of volumetric feeders are available. The most common are single-screw feeders. The volumetric feed rate is proportional to the screw speed. Use of a twin screw instead of a single screw improves the feeding accuracy, but with higher manufacturing cost.

\section{Gravimetric Feeding Devices}

Gravimetric feeders meter the weight of the dry ingredients, which gives more precision than the volume metering used with the volumetric devices. Gravimetric feeders are used more commonly in large-scale extrusion systems. They include weigh-belt and loss-inweight feeders. Both feeders monitor the quantity of dry ingredients and adjust the feed rate accordingly, if any deviation is detected.

\section{LIQUID FEEDERS}

Common liquid raw materials used in extrusion include water, fat, and syrup. Metering of liquid ingredients is critical for successful product manufacturing. Metering of liquids can be achieved either by volume or by mass. Mass flow meters are more accurate than volumetric meters. Devices include rotameters, differential pressure meters, fluid displacement meter, velocity flow meters, and mass flow meters. 


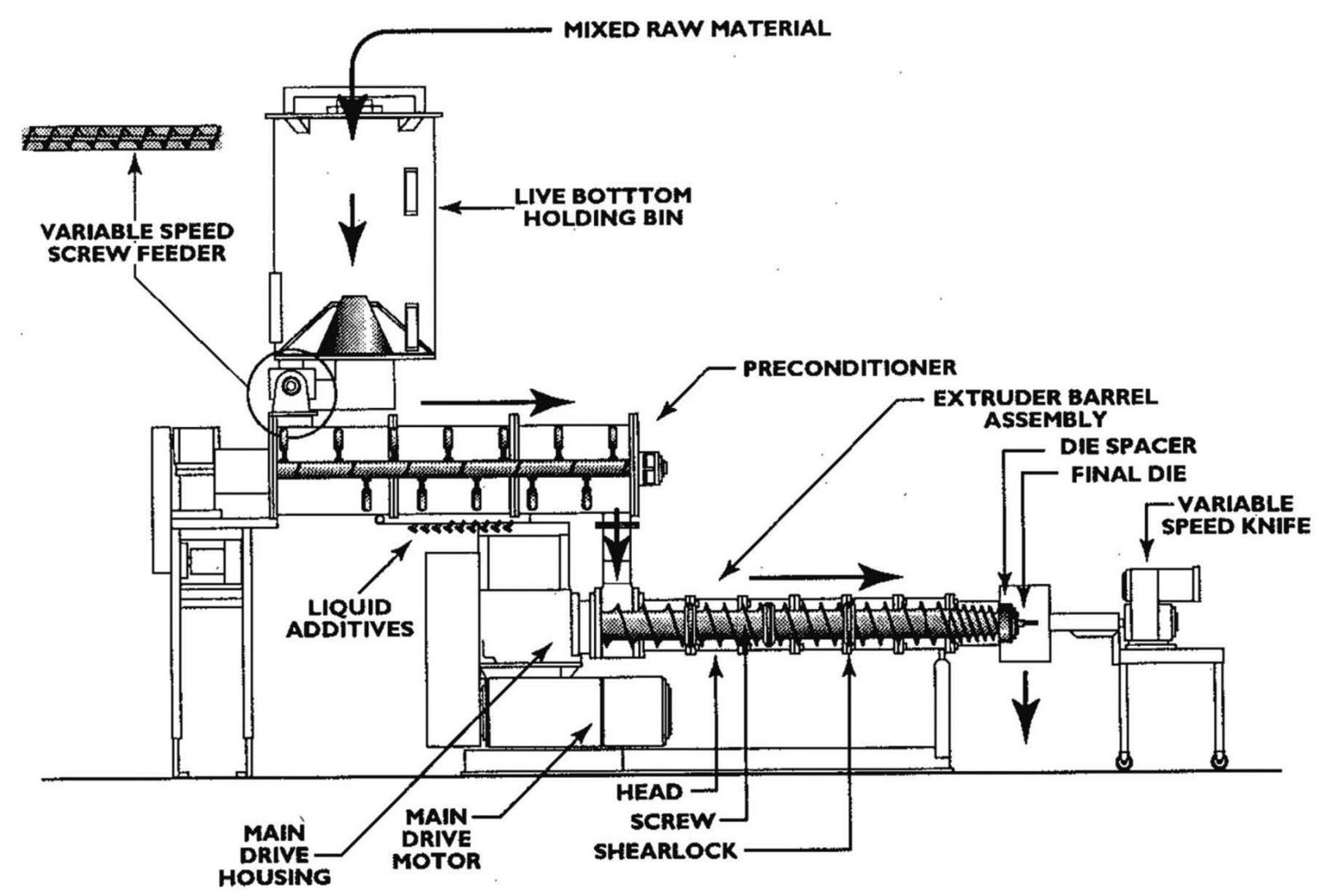

Figure 1. General view of an extruder system. Source: Reprinted from Single screw extruder, in Extruders in Food Applications.[1]

PRECONDITIONER The most important functions of a preconditioner are moisture adjustment and precooking of the raw materials prior to extrusion. During preconditioning, raw materials are held in a warm, moist environment where they are mixed for a prescribed time, and then discharged into the extruder. Preconditioning provides the benefits of improved product quality, reduced extruder wear, increased extruder capacity, and reduced power consumption.

Preconditioners are mounted between the feeding device and the extruder. Originally, preconditioners were of a single-shaft design. The shaft, having mixing elements, rotated at relatively high speeds, resulting in retention times of 30 seconds or less. That was insufficient. Most modern preconditioners have a double-shaft design as shown in Figure 2. The two shafts have different dimensions, and rotate at different speeds, which result in improved mixing, and retention times of between 2 and 4 minutes.

Preconditioners can be operated at either atmospheric pressure or elevated pressure. Preconditioning at elevated pressure increases cooking temperature to above $100^{\circ} \mathrm{C}$, which is sometimes advantageous. However, they are more complex and cost more to purchase and maintain. During preconditioning, steam and/ or water are supplied to increase the temperature and moisture content of the raw materials. Steam is added from the bottom of the preconditioner while hot water $\left(80-90^{\circ} \mathrm{C}\right)$ is added from the top through spray nozzles, for uniform distribution.

\section{EXTRUDER ASSEMBLY}

Extruders can be classified by the number of screws used. There are two basic designs: single-screw extruders

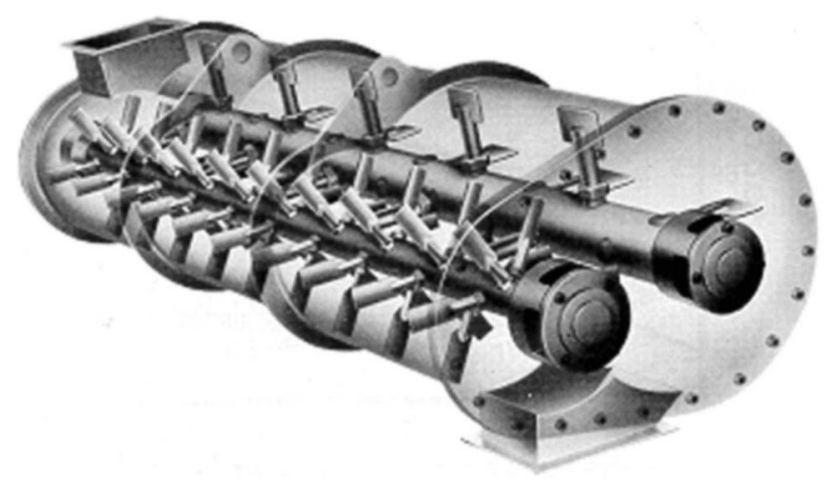

Figure 2. Double-shaft preconditioner. 


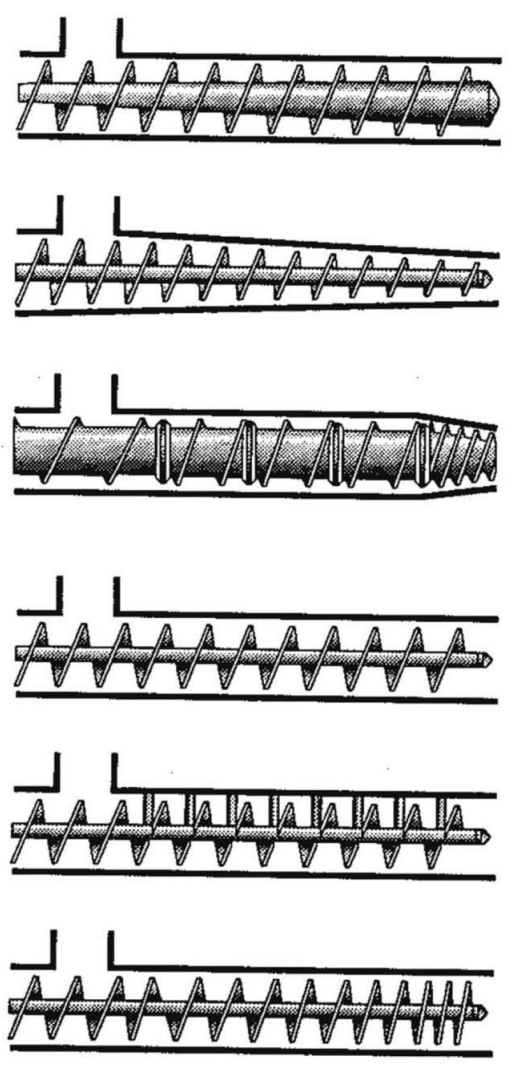

CONSTANT PITCH, INCREASING

ROOT DIAMETER

CONSTANT PITCH, CONSTANT ROOT DIAMETER, DECREASING DIAMETER

\section{VARIABLE PITCH, CONSTANT DEPTH, INCREASING ROOT DIAMETER, INCREASING NUMBER OF FLIGHTS, SHEARLOCKS, DECREASING DIAMETER}

\section{CONSTANT PITCH,}

CONSTANT ROOT DIAMETER

\section{CONSTANT PITCH \\ CONSTANT ROOT'DIAMETER \\ WITH BREAKER BOLTS}

DECREASING PITCH,

CONSTANT ROOT

Figure 3. Common screw configurations for a single-screw extruder. Source: Reprinted from Single screw extruder, in Extruders in Food Applications.[1]

and twin-screw extruders. A single-screw extruder is simple in design, easy to maintain, and provides satisfactory functionality. Twin-screw extruders, on the other hand, are more versatile in that they can handle raw materials with a wider range of characteristics. For large-scale extruders, the screws are made in segments so that various screw configurations can be achieved to meet the processing requirements of a particular product and different products. When needed, various screw segments with different processing functions, such as conveying, kneading, mixing, shearing, and compression, can be configured to meet the processing requirements of a specific product.

\section{Single-Screw Extruder Assembly}

A single-screw extruder assembly consists of a screw and a barrel. The conventional practice is to rotate the screw within a stationary barrel, but the converse is available. Depending on the processing requirements, several types of screw configurations are available as shown in Figure 3. Different screw configurations provide different shearing conditions and pressure profiles, which are uniquely suited for the production of different products. According to Harper,[3] the extruder bar- rel for a single-screw extruder can be divided into three sections in terms of functionality: feeding, compression, and final metering zones, as shown in Figure 4. Along the length of the screw, compression increases from the feeding zone to the final metering zone. The main function of the feeding zone is to push the incoming raw materials to the subsequent metering zone, forming a continuous flow of mass within the barrel. The screw conveying capability is determined by the screw geometry, i.e., the pitch, flight angle, and flight depth. The flight of a screw is the helical conveying surface of the screw to push the product forward. The pitch of a screw is the axial distance of a full flight circle. The flight angle is defined as the angle of the flight relative to the axis of the screw shaft. Generally, screw feeding zones have relatively deep flights, large pitches, and large flight angles to enhance conveying capacity. As the raw material is conveyed to the metering zone, it starts melting due to the thermal energy input from the barrel wall as well as from the dissipation of mechanical energy. Within the compression zone, additional mixing can be accomplished by means of special screw elements, such as kneading blocks and interrupted flights. At the end of the compression zone, the material is fully melted, exhibiting a rubbery behavior similar to flour dough. 


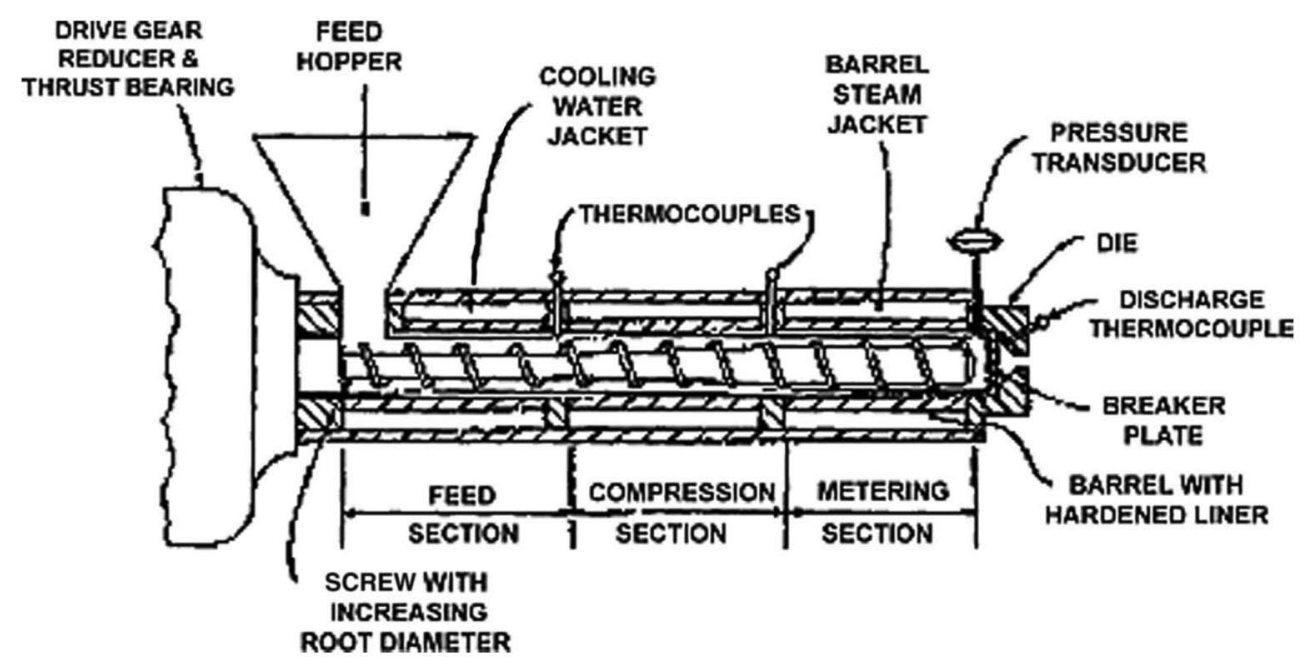

Figure 4. Extruder barrel zones. Source: From The food extruder, in Extrusion of Foods.[3]

In the final metering zone, the dough is further compressed by the shallow flights and short pitches of the screw. The dough is fully cooked before exiting the extruder die.

In many extruders, a heating/cooling medium flows through a jacket surrounding the extruder barrel. Heating is typically accomplished with overheated steam or hot oil. Cooling is achieved with tap water. The inside surface of the barrel can be smooth or grooved to prevent the dough from rotating with the screw. The barrels of many commercial extruders are segmented and individually jacketed so that different temperature profiles can be achieved.

\section{Twin-Screw Extruder Assembly}

Twin-screw extruders are now popular in the food industry because they can process a wider variety of materials, including high-moisture and sticky materials, than single-screw extruders. The versatility of the twinscrew extruder makes it suitable for manufacturing a wider range of products. On the basis of the relative positions of the screws and their directions of rotation, twin-screw extruders can have four possible screw configurations (Figure 5), i.e., countercorotating with intermeshing; corotating with intermeshing; self-wiping, and non-intermeshing.

The food industry most often uses twin-screw extruders with corotating intermeshing configurations because they are self-cleaning, achieve efficient mixing, produce moderate shearing forces, and have higher capacities. The barrel of a twin-screw extruder, like the barrel of the single-screw extruder, is divided into three zones: feeding, kneading, and final cooking. These zones have processing functions similar to those of a single-screw extruder.

\section{VENTING PORTS}

Openings can be provided in the barrels of both singlescrew and twin-screw extruders to allow moisture and other volatile gases to be removed from the dough. The venting ports are located in the middle or end sections of the barrel. The removal of moisture from the dough reduces product expansion, which is beneficial for nonexpanded foods and for adjusting the density of aquatic

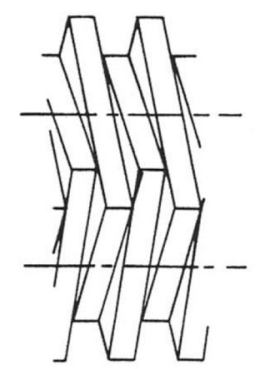

a

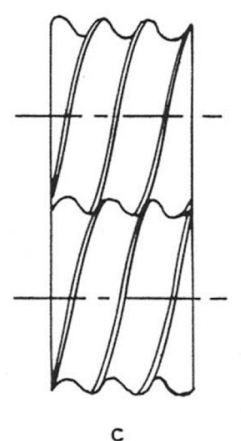

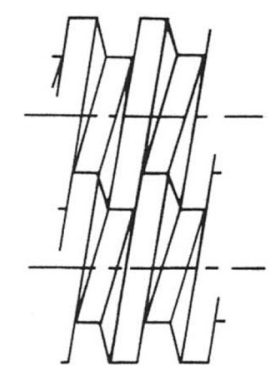

b

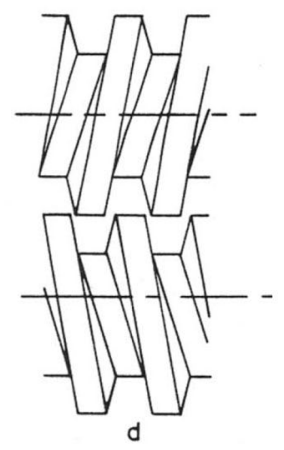

Figure 5. Classifications of twin-screw extruder. (a) Countercorotating with intermeshing; (b) corotating with intermeshing; (c) self-wiping; and (d) non-intermeshing. Source: Reprinted from Engineering aspects of food extrusion, in Extrusion Cooking.[4] 
foods that must sink or be suspended beneath the surface when placed in water.

\section{DIE ASSEMBLY}

The die plate functions as a restriction and forming device mounted at the end of the barrel. By adjusting the die opening, the pressure, retention time, and the dimensions and shape of the final product can be controlled. For smallscale extruders, the die assembly has only one opening. Multiple openings are available for large- or commercialscale extruders.

\section{CUTTER}

A cutter consists of a group of rotating knives mounted in front of the die plate. Cutters are used to cut the extrudate into finite lengths. The rotational speed of the knives is adjustable. The length of extrudate is determined by the number of knives and the rotational speed of the knives.

\section{DRIVING UNIT}

The main function of the driving units is to provide power to rotate the extruder screws. Part of the mechanical energy from the driving unit is converted into heat due to friction within the extruder barrel. Depending on the degree of shearing, friction heating can be significant. The extruderdriving unit usually consists of an electric motor, V-belts, and a gearbox. The V-belts and gearbox achieve speed reduction. The power rating of the electric motor is determined by the size of the extruder and the product to be extruded. Low-shearing extruders may require as little as $10 \mathrm{kWhr}$ per ton of throughput, while high-shearing extruders may require as much as $120 \mathrm{kWhr}$ per ton of throughput.[ 4] The gearbox of the single-screw extruder requires only one output shaft to drive the screw, which makes the construction of the gearbox simple. In the twin-screw extruder, the gearbox has two output shafts, rotating at the same speed, to drive the two screws. The limited space in the radial direction makes the bearing arrangement difficult since the bearings have to support both the radial load and the thrust load from the extruder screws. Therefore, a combination of different types of bearings is usually installed in the gearbox.

\section{CONCLUSIONS}

Extrusion systems are complex systems in which the screws, barrel, and die are the main components to accomplish specific food processing tasks. On the other hand, extruders can combine multiple unit operations (mixing, melting, degassing, cooking, and forming) into a single processing step, which provides enormous benefits in terms of saving overall equipment cost, energy, and space. The segmented screw and barrel designs provide for an unlimited number of configurations to satisfy the processing requirements of a wide variety of products. Finally, with the incorporation of computer automation, extrusion processing can ensure high and consistent product quality with minimum human labor cost.

ACKNOWLEDGMENT- The contributions of Dr. Yubin Lan, USDA-ARS, College Station, Texas, to an earlier edition of this entry are acknowledged.

\section{REFERENCES}

1. Rokey, G.J. Single screw extruder. In Extruders in Food Applications; Riaz, M.N., Ed.; Technomic Publishing Co.: Lancaster, PA, 2000; 25-50.

2. Hauck, B.W. Preconditioning Apparatus for Extruder. U.S. patent 4,752,139, June 21, 1988.

3. Harper, J.M. The food extruder. In Extrusion of Foods; Harper, J.M., Ed.; CRC Press, Inc.: Boca Raton, FL, 1981; 7-19.

4. Janssen, L.P.B.M. Engineering aspects of food extrusion. In Extrusion Cooking; Mercier, C., Linko, P., Harper, J.M., Eds.; American Association of Cereal Chemists, Inc.: St. Paul, MN, 1989; 17-38. 